\title{
Wind Energy Reliability Analysis based on Monte Carlo Simulation Method
}

\author{
Khaled Abdusamad* \\ Mechanical Engineering Department, Garaboulli Engineering Faculty, Elmergib University, Libya \\ DOI: https://doi.org/10.21467/proceedings.4.41 \\ * Corresponding author email: kmatok70@gmail.com
}

\begin{abstract}
Reliability is defined as the probability that an item will continue to achieve its intended function without failure for a specified period of time under operation conditions. The challenges of addressing energy supply and climate change are expected to drive the growth of renewable-based electrical generation such as from wind. Consequently, worldwide growth in wind energy is expected to increase as more wind turbines are installed to meet clean electricity demand and decrease the usage of fossil fuel. However, wind has risks and uncertainties that need to be addressed, perhaps the most significant challenge wind speed variability, which emphasizes that it cannot be considered as a reliable means of meeting the electrical loads. This paper suggests a Monte Carlo summation method, which can be utilized to apply reliability analysis in order to obtain the most-likely resistance-load relationship and the system probability of failure. A case study, which is based upon collected data from actual measurements, is presented in order to study the performance of a group of wind-turbines that deliver electricity to satisfy the demand of a certain load in a suggested area.
\end{abstract}

Keywords: Reliability, Wind energy, Probability of failure, Monte Carlo summation, Weibull distribution

\section{Introduction}

Due to the increase in the demand of electric power and great trend to integrate the wind energy with different renewable sources, the concept of reliability has become a very important factor in the overall wind energy systems. In the recent years, the production of electric power based on wind energy is developing remarkably, which results great development in the performance of wind turbines in general. The main factor in making wind energy industry more efficient is improvement the reliability of wind turbine performance. This has led to many wind turbine reliability models being developed. Therefore, it is very significant to continue developing new and accurate reliability models. Researchers have recognized the advantages of integrating both reliability and performance in a consolidated mathematical model. For instance, a reliability evaluation of a laboratory-based Micro Grid system consisting

(C) 2018 Copyright held by the author(s). Published by AIJR Publisher in Proceedings of First Conference for Engineering

Sciences and Technology (CEST-2018), September 25-27, 2018, vol. 2 .
This is an open access article under Creative Commons Attribution-NonCommercial 4.0 International (CC BY-NC 4.0)

A iR license, which permits any non-commercial use, distribution, adaptation, and reproduction in any medium, as long as the original work is properly cited. ISBN: 978-81-936820-6-7 
Wind Energy Reliability Analysis based on Monte Carlo Simulation Method

of wind, is proposed using a Monte Carlo Simulation method for the system well-being analysis [1]. The study showed the system well-being computation index provided a bridge between the deterministic and probabilistic methods and defined indices that can be useful in a practical Micro Grid reliability evaluation. In another study conducted by Sameer Vittal et. al, the system performance and reliability analysis of wind turbines using Monte Carlo methods based on system transport theory was utilized to develop a performability model of extremeweather wind turbines [2]. An enhanced model for calculation of reliability indices for different wind power plants configuration concepts was studied [3]. The autoregressive moving average model was used combined with the sequential Monte Carlo simulation in order to predict the expected energy not served more accurately during the failure. K. Hagkwen, and C. Singh suggested a reliability simulation in wind farm with different wind turbines at different heights, and it was found that as the height of some wind turbines is higher, energy loss by wake effect drops due to shear effect [4]. A new Monte Carlo simulation procedure and nearby regional weather station data are used to predict wind speed and turbine energy. The results indicated that the replacement of on-site wind data can replace provide accurate predictions of proposed nearby wind turbine [5]. Another computational model using one year of wind speed data of a weather station located downwind of the wind turbine site resulted in the greatest match of simulation results to the measured values. A forecasting method that applies Resistance-Load technique to estimate the reliability of a wind-energy system is studied in. The method is a combination of a prediction and risk-based approach, whereas the prediction technique models the power generation and demand scenarios, while the Resistance-Load technique, estimates reliability of the system [6].

The current work presents an application of Monte Carlo summation method, which can be utilized to estimate the reliability of the wind energy system. In this study, probability of failure is a significant parameter to determine the proposed target through obtaining the most-likely resistance-load and performance relationship. The following sections of the current paper is arranged as follows: Section 2 presents background about Monte Carlo simulation method procedure. Section 3 explains the methodology of the proposed model and the utilization of ResistanceLoad technique to estimate the system performance based on its requirements. In order to demonstrate the use of the proposed method and its capability, case study is provided in Section 4. The obtained results and discussion regarding the proposed model are showed in Section 5. Finally, conclusions and suggestions for further research are presented in Section 6.

\section{Monte Carlo Simulation}

Monte Carlo simulation is a powerful statistical analysis tool, which widely used in engineering fields to evaluate the probability of failure of the energy systems. This simulation performs random sampling and conducts a large number of experiments on computer, which displays the statistical characteristics of the model outputs to their distributions. The outline of Monte Carlo simulation consists of three steps, which is illustrated in Figure 1. In step 1, the 
cumulative distribution functions $(\mathrm{CDF})$ of the random variable is equated to the generated random number $u_{i}$, that is, $F_{X}\left(x_{i}\right)=u_{i}$, and the equation is solved for $x_{i}$ as follows $[7,8]$ :

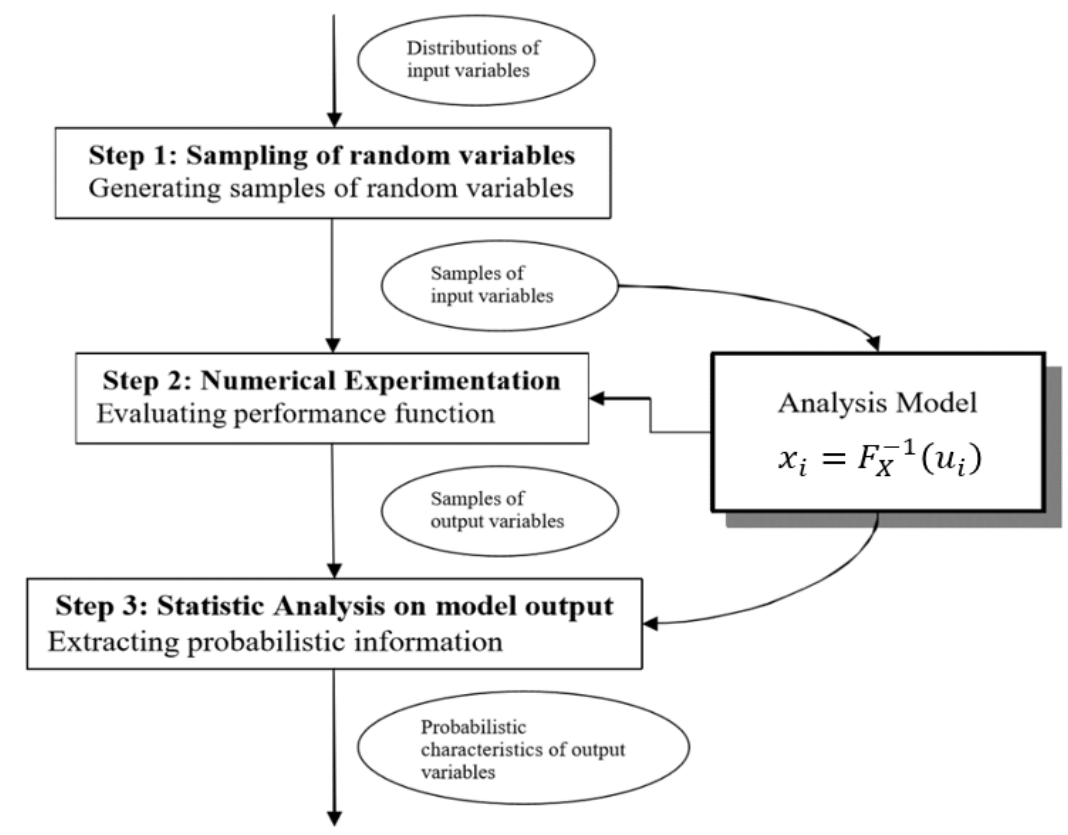

Figure 1: Monte Carlo Simulation Technique [7-10]

$x_{i}=F_{X}^{-1}\left(u_{i}\right)$

Evaluating the performance function represented in step 2. If the random variable $\mathrm{X}$ with parameters $\lambda_{X}$ and $\zeta_{X}$ is lognormally distributed, the $i t h$ random number $x_{i}$ according to the lognormal distribution can be generated.

$\ln \left(x_{i}\right)=\lambda_{X}+\zeta_{X} \phi^{-1}\left(u_{i}\right)$

$u_{i}=\phi\left(\frac{\ln \left(x_{i}\right)-\lambda_{X}}{\zeta_{X}}\right)$

$x_{i}=\exp \left(\lambda_{X}+\zeta_{X} \phi^{-1}\left(u_{i}\right)\right)$

where $u_{i}$ is random number $(0$ and 1$)$, and where $\lambda_{X}$ and $\zeta_{X}$ are the two parameters of the lognormal distribution. A computer program can be written to generate random numbers according to any distribution. In fact, many available computer programs can generate random numbers for commonly used distributions. If the computer cannot generate a specific distribution, Eq. (1) can be used to obtain it. In step 3, statistical analysis on the proposed model are applied in order to extracting probabilistic information through multiple tries [911]. Resistance-Load is an application of Monte Carlo technique, which widely used for the reliability assessment of systems having a certain "resistance", R, against an applied "load", L. The technique is utilized for an energy system considers the random nature of electrical generation and load simultaneously. The basic concept of Resistance-Load technique is that 
Wind Energy Reliability Analysis based on Monte Carlo Simulation Method

energy systems are considered reliable when power generation i.e. $R$, exceeds $L$ value. Consequently, the probability of $\mathrm{R}>\mathrm{L}$ can be determined by employing this method, which submits an expectation about the energy reliability of the selected wind farm. Forecasting reliability using $\mathrm{R}-\mathrm{L}$ technique consists of several steps, which are summarized in the next section [6].

\section{Methodology}

In order to define the reliability of an existing wind energy system based on R-L technique, several steps must be considered. First, identifying of the random and deterministic variables of the proposed model should be taken into consideration to analyse the probability distribution of both variables. Then, determine the respective probability distribution parameters is required before modelling the R-L values. Finally, Monte Carlo simulation is applied to estimate the probability of failure of the entire system [6].

\subsection{Identifying the Random and Deterministic Variables of the System}

Forecasting reliability using Monte Carlo simulation based Resistance-Load technique requires identifying the random and deterministic variables of the proposed model. In this work, $\mathrm{R}$ represents the total energy output generated by the selected wind farm over several years; modeling its value requires simulated wind speeds (v) and system losses (loss). The generated power by a single wind turbine rotor is determined according to the following relation [12-14] :

$P_{W}=\frac{1}{2} A \rho_{a} C_{P} v^{3}$

where, $P_{w}$ represents the generated or produced power by the rotor of a wind turbine, $\rho_{a}$ is the air density, $v$ is the wind speed, $A$ is the rotor swept area of a wind turbine, and $C p$ is the performance coefficient of a wind turbine. System losses for a known probability distribution are simulated using distribution parameters, such as, mean and variance through Monte-Carlo simulation technique. The model of the system is described as follows:

Performance $=\left(\frac{1}{2} A \rho_{a} C_{P} v^{3}-\right.$ losses $)-$ Load

The random variables of the proposed model are:

1-The air density $\rho_{a}\left(\frac{\mathrm{m}^{3}}{\mathrm{~kg}}\right) \quad$ 2-The wind speed $v(\mathrm{~m} / \mathrm{s}) \quad$ 3-The demeaned load L (Watt)

The deterministic variables of the system are:

1- The swept area of the wind turbine rotor $\mathrm{A}\left(\mathrm{m}^{2}\right)$ refers to the area of the circle created by the blades as they sweep through the air.

2- Wind turbine power coefficient $C_{p}$, which is defined as the proration of the produced power by the wind turbine's generator to the power in the wind. The system losses is determined according to listed in Table 1 : 
Table 1: Summary Losses value is the wind turbines [6]

\begin{tabular}{|l|c|}
\hline \multicolumn{1}{|c|}{ Type of Loss } & Value (\%) \\
\hline WTG Unavailability $\left(\operatorname{loss}_{1}\right)$ & 3 \\
\hline Collection and Substation Unavailability $\left(\operatorname{loss}_{2}\right)$ & 0.5 \\
\hline Electrical and Transmission Loss $\left(\operatorname{loss}_{3}\right)$ & 2 \\
\hline Utility/Grid Unavailability $\left(\operatorname{loss}_{4}\right)$ & 0.5 \\
\hline King and Blade Degradation $\left(\operatorname{loss}_{5}\right)$ & 3 \\
\hline Wake Induced Turbulence Loss $\left(\operatorname{loss}_{6}\right)$ & 5 \\
\hline
\end{tabular}

The total system losses can be calculated from the next formula:

$$
P_{\text {loss }}=\left(\operatorname{loss}_{1}+\operatorname{loss}_{1} \ldots \ldots+\operatorname{loss}_{1}\right) / 100 * N_{T} * P_{\text {out }}
$$

where $\mathrm{N}_{\mathrm{T}}$ is the number of wind turbines in a wind farm.

\subsection{Probability Distribution Analysis}

In order to analyse the probability distributions for the wind speed, losses and load, graphical techniques, such as histogram and probability plot are required. Furthermore, modelling $\mathrm{R}$ and $\mathrm{L}$ values is based on distribution parameters and simulation techniques. By using EasyFit software, the best wind speed distribution can be obtained. The software allows using different types of distributions and compare then in terms of some tests such as K-S test, Chi square test, and Anderson darling test. To obtain simulated wind speeds, probability distribution identification is required based on historical wind speed data. In line with pervious work, the current study's wind speed distribution can be described using Weibull distribution when Chi square test considered $[9,10]$ The Weibull distribution is represented by two-parameter; Weibull shape parameter $(K)$, and Weibull scale parameter $C$, which are determined based on the mean $(\bar{v})$ and standard deviation $\left(\sigma_{v}\right)$ of wind data [15-17].

$$
\begin{aligned}
& K=\left(\frac{\sigma_{v}}{\bar{v} .}\right)^{-1.086} \\
& \frac{C}{\bar{v}}=\left(0.568+\frac{0.433}{K}\right)^{-1 / K}
\end{aligned}
$$

Weibull shape parameter, $\mathrm{k}$, generally ranges from 1.5 to 4 for most wind conditions. In addition, Weibull distribution whose cumulative distribution function (CDF) is given as follows [15-17]:

$F(v)=P[V \leq v)=\int_{0}^{v} f(v) d v=1-\exp \left\{-\left(\frac{v}{C}\right)^{K}\right\}$

where $P(\leq v)$ is the probability of the measured wind speed is less than or equal $v$. Figure 2 illustrates the effect of the shape parameter on the cumulative distribution function. Equation 11 presents the definition of the Weibull probability density function. Figure 3 displays the effect of the shape parameter on the probability density function [15-17]. 
$f(v)=(v)=\left(\frac{k}{c}\right)\left(\frac{v}{c}\right)^{k-1} \exp \left[-\left(\frac{v}{c}\right)^{k}\right]$

When the shape parameter $\mathrm{K}$ is equal to 2, the P.D.F. is given its own name, the Rayleigh probability density function, which is defined as follows [15-17]:

$f(v)=\frac{2 V}{c^{2}} * \exp \left[-\left(\frac{v}{c}\right)^{2}\right]$

The equation of the cumulative Rayleigh function is defined as follows [15-17]:

$F(v)=1-\exp \left[-\frac{\pi}{4} *\left(\frac{v_{i}}{\bar{v}}\right)^{2}\right]$

\subsection{Modelling the Resistance (R) and Load (L) Values.}

An energy system's load is considered independent of wind speed, and the resistance represents the total electrical output generated by the wind turbines over several years. Modelling R-L values requires first simulated wind speeds $(v)$, air density $\left(\rho_{a}\right)$, and system losses (loss).

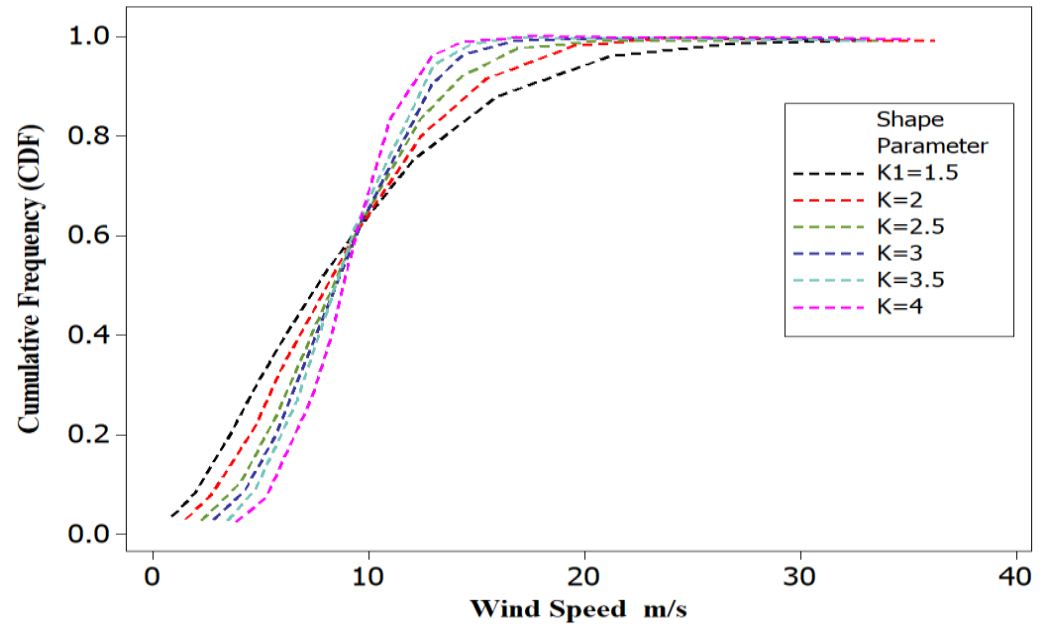

Figure 2: The Effect of the Shape Parameter on the Cumulative Distribution Function

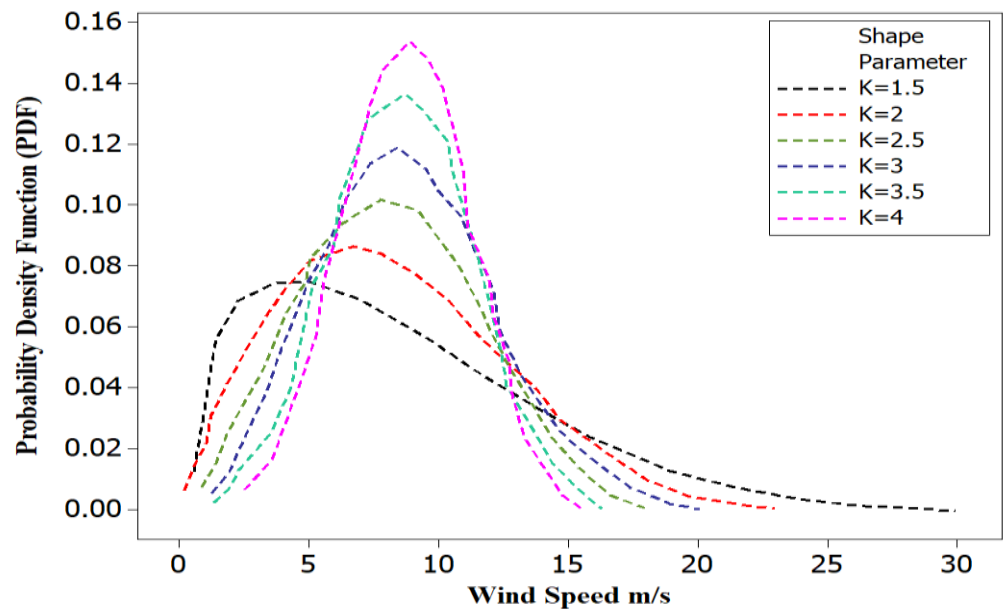

Figure 3: The Effect of the Shape Parameter on the Probability Density Function 
Using the simulated losses and wind speeds, the net generated $P_{N E T}$ from each wind turbine is calculated from the following equation:

$P_{N E T}=P_{w}-P_{L O S S}$

The reliability of the proposed system is carried out to study the probability of failure to satisfy the load power demand and calculate $\mathrm{P}(\mathrm{R}<\mathrm{L})$. The total net power (resistance) is determined as follows:

The total net power $(R)=N_{T} * P_{N E T}$

\subsection{Determine the Probability of Failure}

The probability of failure represents the probability of failure, which requires a knowledge about the wind turbine specification. In this issue, the power curve of each single wind turbine displays the required specification to apply Monte Carlo simulation.

\section{Case Study}

In order to utilize the proposed model to determine the reliability of the wind energy systems, collected data, which are related to an area in Tripoli -Libya is selected [18]. The specifications that are selected to be set up in the area are illustrated in Table 2 [19]. In of the wind turbines addition, Fig, 4, which shows the dependence between wind speed and produced electrical power of the selected wind turbine. It can be realized that there are three stages should be explained. Stage 1 occurs when the wind speed between $(3 \mathrm{~m} / \mathrm{s})$ to the rated speed $(11 \mathrm{~m} / \mathrm{s})$. Then, stage 2 occurs when the wind speed between the rated speed $(11 \mathrm{~m} / \mathrm{s})$ to the cut off speed $(20 \mathrm{~m} / \mathrm{s})$. Finally, stage 3 occurs when the wind speed more than or equal the cut off speed at $(20 \mathrm{~m} / \mathrm{s})$. Therefore, there is a need to find the produced power at each stage for each turbine in the proposed wind farm, which can be determined as follows:

- Stage 1: $\mathrm{P}_{\text {produced }}=\frac{1}{2} \mathrm{~A} \rho_{\mathrm{a}} \mathrm{C}_{\mathrm{P}} \mathrm{v}^{3}-$ Losses - Stage 2: $\mathrm{P}_{\text {poduced }}=1057 \mathrm{KW}-$ losses

$$
\text { -Stage 3: } \mathrm{P}_{\text {out }}=0 \mathrm{~W}
$$

Table 2: 1057kW Wind Turbine General Specification [19]

\begin{tabular}{|r|c|}
\hline Category & Specification \\
\hline Rated Power & 10571057 \\
\hline Number of Blades & 3 blades \\
\hline Rotor Diameter & $60 \mathrm{~m}$ \\
\hline Cut-In Wind Speed & $3 \mathrm{~m} / \mathrm{s}$ \\
\hline Rated Wind Speed & $11 / \mathrm{m} / \mathrm{s}$ \\
\hline Hub Height & $66 \mathrm{~m}$ \\
\hline Cut-Out Wind Speed & $20 \mathrm{~m} / \mathrm{s}$ \\
\hline Coefficient of Power & $40 \%$ \\
\hline
\end{tabular}

Proceedings of First Conference for Engineering Sciences and Technology (CEST-2018), vol. 2 


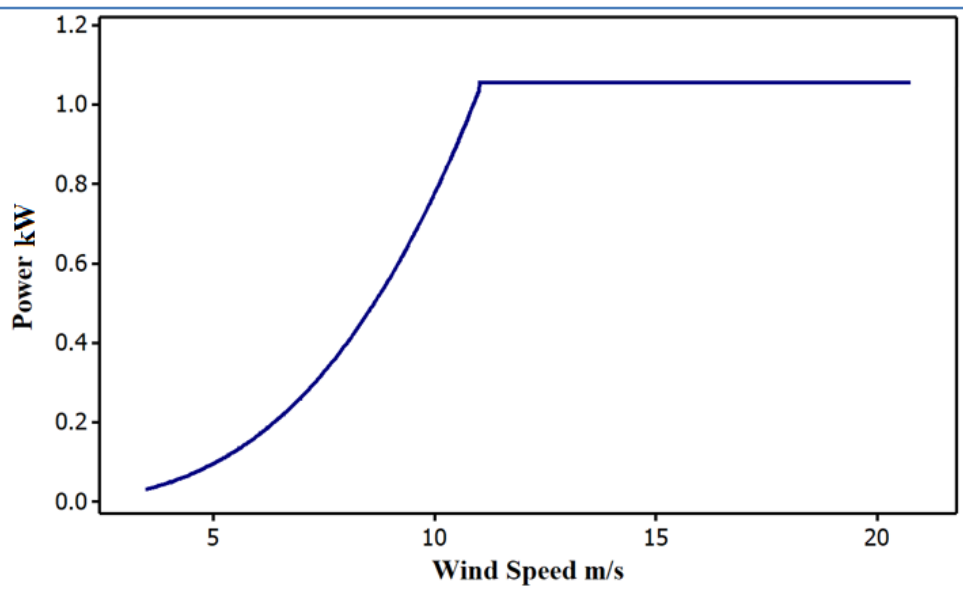

Figure 4: 1057kW Wind Turbine power curve

The obtained data is representing in the average of wind speeds, air pressures, and temperatures for every day in the year during the study period of the selected area. Figure 5 displays the fluctuations of the average wind speed throughout the study for the same location [18]. Since, the obtained wind speed data are measured at $10 \mathrm{~m}$, an adjustment must be made to obtain wind speeds at the turbine hub height. Several common functions that describe the change in mean wind speed with height are utilized. With the aid of Eq. 15, the average wind speed at the turbine hub height is determined.

$v_{z}=v_{R} *\left(\frac{Z}{Z_{R}}\right)^{\alpha}$

where $\alpha$ is the friction coefficient for various terrain characteristics, which is determined from Table 3. Finally, the suggested wind farm consists of twenty-wind turbine to cover the load in the selected area. Section 5 presents the results that obtained from applying the proposed model.

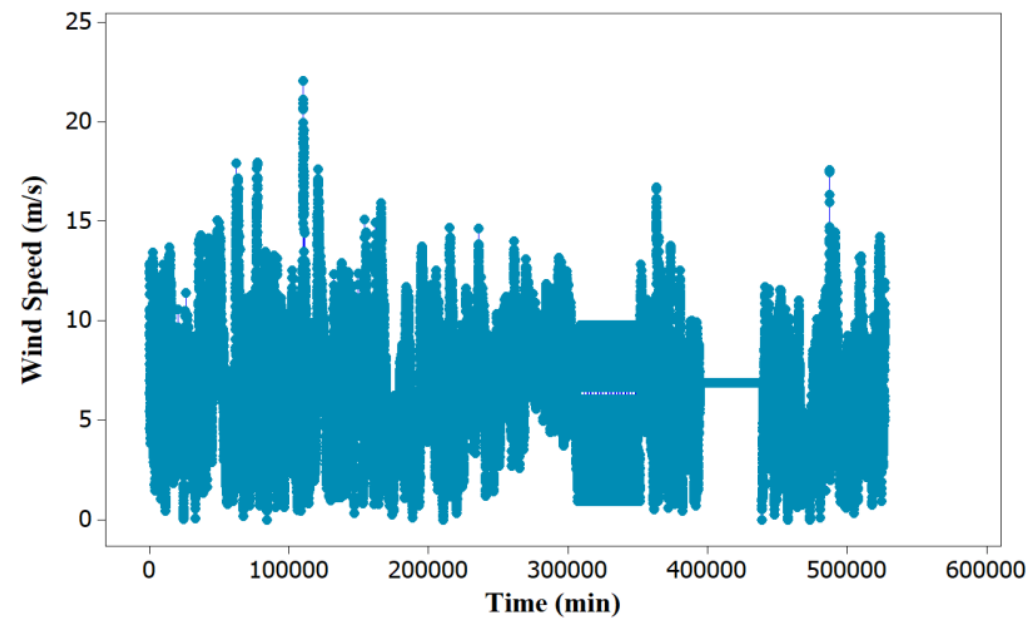

Figure 5: The fluctuations of the average wind speed during the duration of the study [18] 
Khaled Abdusamad, CEST-2018, AIJR Proceedings 4, pp.734-745, 2018

Table 3: The friction coefficient for various terrain characteristics [12,13]

\begin{tabular}{|l|c|c|}
\hline \multicolumn{1}{|c|}{ Type of terrain } & Roughness class & $\beta$ \\
\hline Water areas & 0 & 0.01 \\
\hline Open country, few surface Features & 1 & 0.12 \\
\hline Farm land with building and hedges & 2 & 0.16 \\
\hline Farm land with many trees, Forests, villages & 3 & 0.28 \\
\hline
\end{tabular}

\section{Results and Discussion}

The obtained results indicate that there is dramatic changes in the wind speed when it reaches $9 \mathrm{~m} / \mathrm{s}$. The performance before this value is negative, which means the demand power of the selected area is greater than the produced power by the proposed wind farm. Figure 6 displays wind speed time series with respect to its frequency. The diagram shows that most available wind speeds range from $9 \mathrm{~m} / \mathrm{s}$ to $10 \mathrm{~m} / \mathrm{s}$. Figure 7 shows the Weibull probability density function and cumulative distribution function of the wind speed. Weibull probability density function curve displays the wind speed probability distribution of the obtained wind speed data. Furthermore, Weibull cumulative distribution curve describes the probability that every single value of the obtained wind speed data takes a value less than or equal to the wind speed variable. The curve shows that the likelihood of the selected wind turbines operating at the rated speed is approximately $25 \%$. The behaviour of the performance of the proposed system with respect to the wind speeds is illustrated in Fig 8. It is obvious that the performance reaches $129 \mathrm{MW}$ at $20 \mathrm{~m} / \mathrm{s}$ but the frequency of this value is low. However, when wind speed is between (3-8) $\mathrm{m} / \mathrm{s}$, the system performance is negative, which submits an indication that the probability of failure of the proposed system in this range is significant value. Table 4 presents details regarding the system generated power against the load of the selected area. The Monte Carlo simulation results are illustrated in Table 5 with several trails. It is noted that as the number of simulations is increase the probability of failure converges, computation error decreases and run time increases significantly.

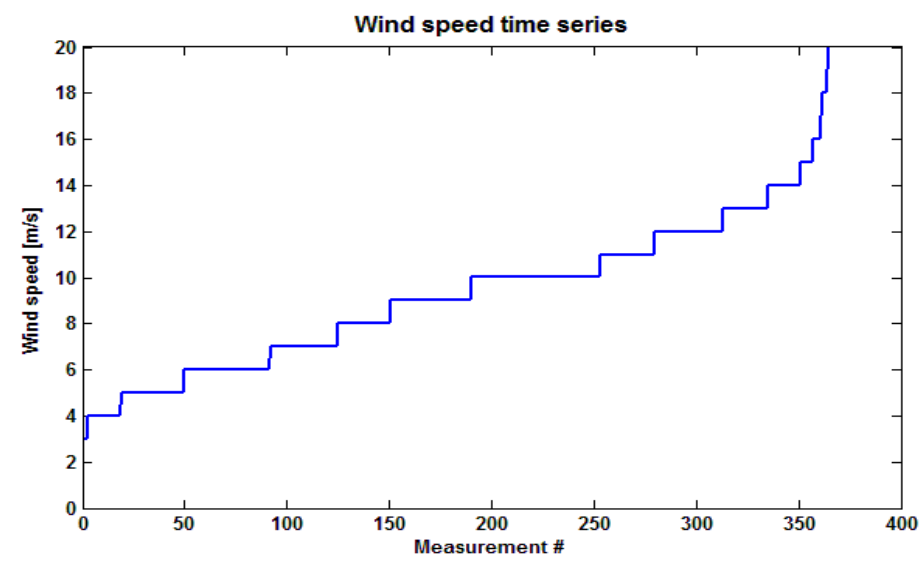

Figure 6: Wind speed time series 
Wind Energy Reliability Analysis based on Monte Carlo Simulation Method

Weibull probability density function

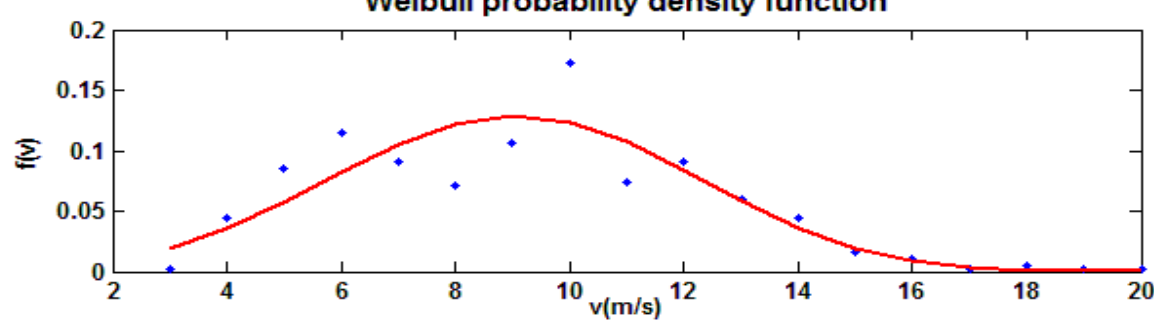

Cumulative Weibull probability density function

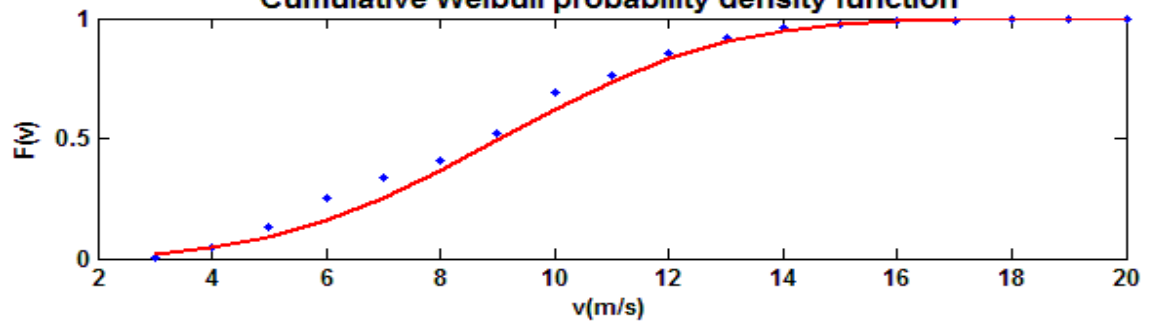

Figure 7: Weibull probability density function and cumulative distribution function

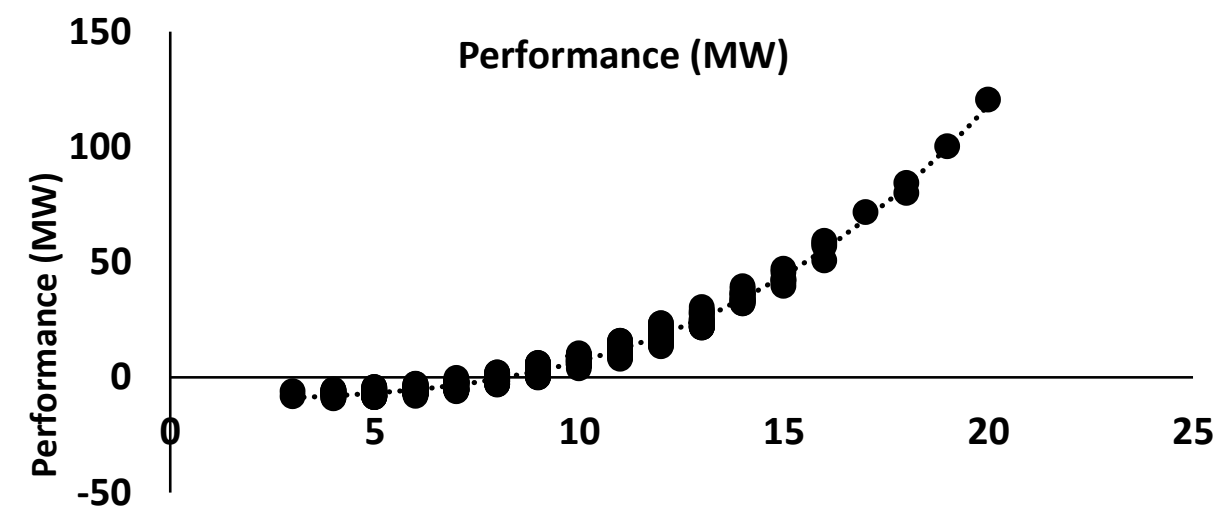

Wind speed $(\mathrm{m} / \mathrm{s})$

Figure 8: The trend of the system performance with respect to the wind speed

Table 4: The system simulation results

\begin{tabular}{|c|c|c|c|c|c|c|c|}
\hline $\begin{array}{c}\text { Wind speed } \\
\text { m/s }\end{array}$ & $\begin{array}{c}\text { Resistance } \\
\text { MW }\end{array}$ & $\begin{array}{c}\text { Load } \\
\text { MW }\end{array}$ & $\begin{array}{c}\text { Performance } \\
\text { MW }\end{array}$ & $\begin{array}{c}\text { Wind speed } \\
\text { m/s }\end{array}$ & $\begin{array}{c}\text { Resistance } \\
\text { MW }\end{array}$ & $\begin{array}{c}\text { Load } \\
\text { MW }\end{array}$ & $\begin{array}{c}\text { Performance } \\
\text { MW }\end{array}$ \\
\hline 3 & 0.7 & 7.9 & $7.3-$ & 12 & 27.1 & 9.0 & 18.0 \\
\hline 4 & 1.1 & 8.2 & $7.1-$ & 13 & 33.8 & 9.2 & 24.6 \\
\hline 5 & 2.1 & 9.1 & $7.0-$ & 14 & 43.3 & 8.4 & 34.9 \\
\hline 6 & 3.4 & 9.3 & $5.9-$ & 15 & 52.1 & 9.1 & 43.0 \\
\hline 7 & 5.2 & 8.8 & $3.6-$ & 16 & 65.0 & 8.9 & 56.2 \\
\hline 8 & 7.7 & 8.4 & $0.7-$ & 17 & 76.9 & 8.0 & 68.9 \\
\hline 9 & 11.3 & 8.5 & 2.7 & 18 & 88.8 & 7.2 & 81.7 \\
\hline 10 & 15.5 & 7.6 & 7.9 & 19 & 114.1 & 8.6 & 105.5 \\
\hline 11 & 20.6 & 8.4 & 12.2 & 20 & 139.3 & 10.0 & 129.3 \\
\hline
\end{tabular}


Khaled Abdusamad, CEST-2018, AIJR Proceedings 4, pp.734-745, 2018

Table 5: System probability of failure and error with several trails numbers

\begin{tabular}{|c|c|c|c|c|}
\hline Number of trails & Number of failures & Pf $(\%)$ & Error $(\%)$ & Simulation time(sec) \\
\hline 10000 & 2530 & 25.3 & 8.6946 & 2.1359 \\
\hline 100000 & 25174 & 25.17 & 2.7449 & 19.979 \\
\hline 1000000 & 252880 & 25.29 & 0.86933 & 2522.8 \\
\hline
\end{tabular}

\section{Conclusions}

In this study, an effective method based on Monte Carlo simulation is performed to determine the reliability of wind energy systems. The proposed technique is represented to obtain the most-likely generated power-power demand and performance relationship to estimate the system probability of failure in the selected area. It is found that as the number of simulations is increase the probability of failure slightly decreases; computation error reduces significantly and run time increases remarkably. Further, it can be summarized that the wind speed has the most influence on the performance of the wind energy systems, then the demanded power. To obtain simulated wind speeds, it was found that wind speed distribution can be described using Weibull distribution when Chi square test considered. This model may be considered as platform and can be used for other locations in Libya. Future work should be focused on different types of wind turbines and several areas in Libya in order to estimate the most proper locations that represent high the reliability of wind energy systems.

\section{References}

[1] Youli, Su, and Ken Nagasaka, "Monte Carlo simulation method used in reliability evaluation of a laboratory-based micro grid," Proceedings of the international multi conference of engineers and computer scientists, Vol 2. 2010..https://pdfs.semanticscholar.org/f26e/969fffc5f035281927cb9670eb25abf8e3f3.pdf

[2] Vittal, Sameer, and Michel Teboul, "Performance and reliability analysis of wind turbines using Monte Carlo methods based on system transport theory," 46th AIAA/ASME/ASCE/AHS/ASC Structures, Structural Dynamics and Materials Conference, p. 2218. 2014. https://arc.aiaa.org/doi/abs/10.2514/6.2005-2218

[3] Topić, Danijel, Damir ŠljivAc, and Marinko STojkov, "Reliability model of different wind power plant configuration using sequential Monte Carlo simulation," Eksploatacja i Niezawodnosc-Maintenance and Reliability, p. 237. Jan, 2016. http://bib.irb.hr/datoteka/632590.EiN_2016-2_article_11.pdf

[4] Kim, Hagkwen, and Chanan Singh, "Reliability Simulation in Wind Farm with Different Wind Turbines," $\begin{array}{lllll}\text { Proceedings of National Power } & \end{array}$ http://www.iitk.ac.in/npsc/Papers/NPSC2012/papers/12170.pdf

[5] Gallagher, Ron, and Andrew Curtis Elmore, "Monte Carlo simulations of wind speed data," Wind Engineering 33(6), p. 661-673. Dec, 2009. http://journals.sagepub.com/doi/abs/10.1260/0309-524x.33.6.661

[6] Chaudhry, Nikhil, and Larry Hughes, "Forecasting the reliability of wind-energy systems: A new approach using the RL technique," Applied energy 96, p. 422-430. Aug, 2012. https://www.sciencedirect.com/science/article/pii/S0306261912001778

[7] Mooney, Christopher Z, “Monte carlo simulation,” Vol. 116. Sage Publications, Apr, 1997.

[8] Christopher, W, "Wind Turbine Reliability: Understanding and Minimizing Wind Turbine Operation and Maintenance Costs,” Department of Energy. 2006.

[9] Rao, Singiresu S., Singiresu S. Rao, and S. S. Rao, “Reliability-based design,” 1992. https://prkwrhnfx07.storage.googleapis.com/MDA3MDUxMTkyNg==07.pdf 
Wind Energy Reliability Analysis based on Monte Carlo Simulation Method

[10] Haldar, Achintya, and Sankaran Mahadevan, "Probability, reliability, and statistical methods in engineering $\begin{array}{lllll}\text { design," New } & \text { York: } & \text { Wiley. } & \text { Vol. } & 1.2000 .\end{array}$ https://prkwrhnfx07.storage.googleapis.com/MDQ3MTMzMTE5OA==07.pdf

[11] Hall, P. L., and J. E. Strutt, "Probabilistic physics-of-failure models for component reliabilities using Monte Carlo simulation and Weibull analysis: a Parametric Study a parametric study," Reliability Engineering \& System Safety. V01 3. p. 233-242. Jun, 2003. https://www.sciencedirect.com/science/article/pii/S0951832003000322

[12] Manwell, James F., Jon G. McGowan, and Anthony L. Rogers, "Wind energy explained: theory, design and application," John Wiley \& Sons. Sep, 2010.

[13] Jain, Pramod, “Wind energy engineering,” McGraw-Hill Education. Jan, 2016.

[14] Gipe, Paul, "Wind energy basics: A guide to small and micro wind system," White River Junction, VT: Chelsea Green publishing company. Mar, 1999.

[15] Murthy, DN Prabhakar, Michael Bulmer, and John A, "Weibull model selection for reliability modelling," Reliability Engineering \& System Safety 86. V01 3. p. 257-267. Dec, 2004. https://www.sciencedirect.com/science/article/pii/S0951832004000237

[16] Xie, M., and Lai, C.D, "Reliability Analysis Using an Additive Weibull Model with Bathtub-shaped Failure Rate Function," Reliability Engineering \& System Safety 52. V01 1. p. 87-93. Apr, 1996. https://www.sciencedirect.com/science/article/pii/0951832095001492

[17] Lai, C. D., Min Xie, and D. N. P. Murthy, "A modified Weibull distribution," IEEE Transactions on reliability 52. V01 1. p. 33-37. Mar, 2003. https://ieeexplore.ieee.org/abstract/document/1179794/

[18] Data. Provided by Center of Solar Energy Research and Studies, 2015

[19] Data of a Variable Speed Wind Turbine, $1057 \mathrm{KW}$ rated power, three phase permanent magnetic type 440/660 V 60 Hz. Provided by Dr. Kathryn Johnson, Colorado School of Mines, 2013 